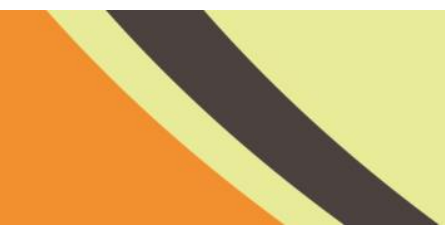

\title{
Academic Quality Compliance of Public Secondary Schools in the City Schools Division of San Jose Del Monte Bulacan: Input to Strengthen Institutional Profiling
}

\author{
Thelma L. Manabat \\ Technological University of the Philippines, Philippines \\ Corresponding Author: manabat thelma@yahoo.com
}

\begin{tabular}{l} 
ARTICLE INFO \\
\hline Article History: \\
Received: 12 October 2020 \\
Final Revision: 12 May 2020 \\
Accepted: 11 June 2020 \\
Online Publication: 15 June 2020 \\
KEYWORDS
\end{tabular}

academic quality compliance, management capability, leadership and governance, curriculum and leaning, accountability and continuous improvement, management resources

\section{CORRESPONDING AUTHOR}

*E-mail: manabat_thelma@yahoo.com

\author{
A B S T $\mathbf{R}$ A C $\mathbf{T}$
}

\begin{abstract}
This study was conducted to determine the level of academic quality compliance of public secondary high schools and its predictors as input to strengthen institutional profiling. The respondents of the study were 167 teachers and school managers in (9) public secondary junior high schools in the City Schools Division of San Jose del Monte Bulacan for the School Year 2017-2018. The descriptive research design was used employing the predictive technique in determining the influence of respondents' profile, institutions' profile variables and the management capability factors as the academic quality compliance of the schools. The findings revealed that the schools' academic quality compliance on leadership and governance is predicted by the NAT (Beta $=.431$ ), promotion rate $(B e t a=1.170)$, and enrollment rate $($ Beta $=.747)$. The management capability on quality instruction predicts the schools' academic quality compliance on curriculum and learning (Beta $=.971$ ) and the academic quality compliance on accountability and continuous improvement is influenced by the management capability on quality instruction. The promotion rate of the school predicts the academic quality compliance of the school in the area of management of resources (Beta =.671). The hypothesis stating that the respondent's profile, institutional profile, and management capability, singly or combination predict the schools' academic quality compliance is partly sustained.
\end{abstract}

\section{INTRODUCTION}

\subsection{Research Background}

Quality education in every learning institution is the foundation of a comprehensive development and the mark of a great and progressive nation. With the quality of education comes the quality of life - a triumph over the clutches of ignorance that seeds the tragedy of poverty. It is the key factor in achieving a sustainable human development that builds new and progressive generations of responsive-creative minds for nation building [1].

In the educational context, excellence in educational quality refers to the overall level of performance or outstanding academic achievements as the primary landmarks for a quality education. Correspondingly such quality education could only be measured and established with the procedural tool of a quality compliance that consists of a systematized evaluation and profiling of institutions, an integrated mission and broad-based goals for the students' development amidst their learning activities and experiences.

Many educational programs fail to achieve the objectives set out at the start because they do not establish a baseline system of quality assurance before the program begins [2]. For this reason the implementation of quality management should integrate a wide variety of issues, such as management, commitment, underestimated cost, insufficient resources, poor communications and resistance to change others with the corresponding establishment and judicious implementation of a standardized measurement or assessment of a quality education known as an academic quality compliance pro-filing program.

\subsection{Literature Review}

\subsubsection{Academic Quality Compliance}

What the school is and what it becomes is determined by the people within it [3]. A school is a social institution consisting of its clientele, stakeholders, and the prime individuals who take full responsibilities of governance particularly the teachers and the administrative staff who work to ensure the success and achievement of the school's organizational goals.

The Institutional Profile of the study defines the Public Secondary Schools through the City Schools Division of San Jose del Monte, Bulacan in terms of the schools' enrolment growth rates, promotion levels, drop-outs, NAT results, research outputs, extension services and management capabilities. Likewise, this 
Institutional profile incorporates the legislatively mandated concern about the students, faculty, trustee, a programme of study, public service activities and major capital projects of the school that is organized according to the "Form and Content" prescription by the Department of Education.

Institutional profiling presents the educational performance of the institution particularly on how well it undertakes or how successfully achieves its mandate, objectives, and responsibilities. In this light, the efficiency and effectiveness of any institution depend heavily on the wholesome attitudes and actions of the staff and administrators [3].

Research findings conducted in 2015, described academic quality compliance as the implementation of the standardized process and pattern of measurement or assessment of the school's quality of learning and academic performance [4]. Quality compliance is a system of rules specifications, policies, standards or laws, therefore compliance is a regulatory evaluation of the educational institutions' goals towards comprehensive standards, policies, laws, and doctrines of quality education [1].

Embedded within this regulatory system of performance evaluation is the operational transparency on consolidated and harmonized sets of compliance controls. This approach is used to ensure that all necessary governance requirements can be met without the unnecessary duplication of effort and activity from resources.

\subsection{Research Objective}

\subsubsection{Statement of the Problem}

The study determined the level of academic quality compliance of public secondary schools in the City Schools Division of San Jose del Monte, Bulacan as an input in strengthening institutional profiling. Specifically, the study sought to answer the following questions:

A. What is the demographic profile of the respondents in terms of: (a). Age; (b). Sex; (c). Civil Status; (d). Length of service; (e). Position; (f). Seminars/ Training attended; (g). Educational Attainment

B. How can the institutional profile be described in terms of: (a). Enrolment; (b). Promotion rate; (c) Drop-out rate; (d). NAT results; (e). Research Outputs; (f). Extension Services

C. How can the institutions' management capability be assessed in terms of their: (a). Administration; (b). Quality of Instruction; (c). Curriculum Enhancement; (d). Research Development; (e). Community relation and linkages; (f). Resources and Facilities

D. What is the level of academic quality compliance as prescribed by the mandate of Department of Education for quality management in accordance to: (a) Leadership and Governance; (b). Curriculum and Learning; (c). Accountability and Continuous Improvement; (d). Management of Resources

E. Do the respondents' profile, institutional profile and the institutional management capability singly or in combination influence the level of the institutions' academic quality compliance?

\subsubsection{Scope and Delimitation}

The study was conducted during the second semester of the Academic Year 2017-2018. It was focused on the level of

14 T. Manabat academic quality compliance of public secondary schools in the City Schools Division of San Jose del Monte Bulacan.

The respondents of the study were limited only to the school heads, administrators, other schools' officers and faculties of public secondary schools in the City Schools Division of San Jose del Monte Bulacan.

The respondents' and schools' profile together with management capability were considered as the independent variables while the level of academic compliance was the dependent variable.

\section{RESEARCH METHODOLOGY}

\subsection{Research Design}

The research design utilized the descriptive method of analysis by profiling the chosen sample of educational institutions in response to the levelling instrument for academic quality compliance set by the Department of Education.

According to Ref. [5], a descriptive study is one in which information is collected without changing or manipulating the environment. Most particularly, the researcher proceeds with the analysis of the institutional profile in terms of enrolment, promotion rate, drop-out rate, research output, extension services and management capability in correlation with the level of academic compliance of public secondary schools thru the pilot school of DepEd San Jose del Monte Bulacan. As such, the methodology of this study is centered on the descriptivecorrelational research process as it delves into the integrated analysis of how variables co-vary with other variables.

The researchers used the descriptive method of research using the survey technique to gather the data needed in the study.

\subsection{Population and Sample}

The study was conducted in nine (9) public secondary junior high schools in the Division of San Jose del Monte Bulacan. Specifically, Sapang Palay National High School, San Jose del Monte National Trade School, San Jose del Monte National High School, Paradise National High School, Kaypian National High School, San Martin National High School, Muzon Harmony Hills High School, San Jose Heights National High School and San Jose del Monte Science High School.

The respondents were composed of the school managers and faculty members. School managers are those performing administrative and supervisory functions based on legal provisions. Faculty members are those engaged in the teachinglearning process having a direct interaction with the learners. Respondents were chosen by a purposive sampling method of selection

\subsection{Instrumentation}

The main data-gathering instrument of this study was based on the researcher-made questionnaire-checklists that have been presented, evaluated, and approved by the members of the research team. The questionnaire had four parts, namely: part one (1) respondents' profile: age, sex, civil status, length of service, position, seminars and training and educational attainment (2) school's profile: enrolment, promotion, drop-out, research outputs and extension services. Part three (3) school's management capability which includes administration, quality of instruction, curriculum enhancement, research development, 
community relation and linkages, and resources and facilities. Part four (4) level of academic quality compliance which includes leadership and governance, curriculum and instruction, accountability, continuous improvement and sustainability of efficient management of resources.

\section{RESULT AND DISCUSSIONS}

The treatment of data reveals the following essential findings.

\subsection{Profile of the Respondents}

The modal profile of the respondents is female (77.2\%), 31 to 40 years old, married $(61.1 \%)$, not more than 5 years in the service $(42.5 \%)$ with M.A units $(61.7 \%)$ and has attended seminars up to Division level (27.5\%).

\subsection{Institutional Profile}

On the average mean, the respondent school has 2205 enrollees, $96 \%$ promotion rate, $2 \%$ dropout rate, with an average of $48 \%$ performance in the NAT, 13.33 average research output, and 8 average number of linkages.

\subsection{Management Capability of the Educational Institutions}

The management capability is rated as "manifested" in terms of administration $(x=3.98)$, quality of instruction $(x=4.14)$ and curriculum enhancement $(\mathrm{x}=3.87)$. Research development having the lowest mean $(\overline{\mathrm{x}}=3.11)$ rated as moderately manifested by the respondents. In terms of research, the majority of the respondent did not conduct research.

\subsection{Level of Academic Quality Compliance}

Respondents' perceptions of leadership and governance $\bar{x}=3.94$ $(\mathrm{SD}=0.742)$; curriculum and Instruction is $\overline{\mathrm{x}}=3.85$; accountability and continuous $\overline{\mathrm{x}}=3.84 \quad(\mathrm{SD}=0.725)$; and management of resources $\bar{x}=3.88 \quad(\mathrm{SD}=0.756)$, indicates agreement on well-observed practices of educational institution and evidently complied with the prescribed mandate of Department of Education for quality management.

\subsection{Predictors of Academic Quality Compliance}

The findings revealed that the schools' academic quality compliance on leadership and governance is predicted by the NAT $($ Beta $=.431)$, promotion rate $($ Beta $=1.170)$, and enrolment rate $($ Beta $=.747)$. The management capability on quality instruction predicts the schools' academic quality compliance on curriculum and learning (Beta $=.971)$ and the academic quality compliance on accountability and continuous improvement is influenced by the management capability on quality instruction. The promotion rate of the school predicts the academic quality compliance of the school in the area of management of resources $($ Beta $=.671)$

\section{CONCLUSION AND RECCOMENDATIONS}

Based on the findings, the following conclusions are drawn.

1) The academic quality compliance on leadership and governance is significantly predicted by the performance in the NAT, promotion rate, and enrolment rate of the school.
2) The management capability on quality instruction predicts significantly the academic quality compliance with curriculum and learning.

3) The management capability on quality instruction predicts significantly the academic quality compliance an accountability and continuous improvement.

4) The academic quality compliance on the management of resources is significantly predicted by the promotion rate of the school.

In as much as, not all independent variables selected in this study do not significantly affect, hence, the null hypothesis stating that the institutional profile and management capability singly or in combination do not influence the academic quality compliance of public secondary schools in the Division of San Jose del Monte, Bulacan is partially sustained.

In the light of the foregoing conclusions, the following recommendations are hereby offered:

1) Strengthen the parent-teacher relationship and follow up the student who quit schooling to reduce the high dropout rate.

2) Adopt the good academic and management practices of PNHS to improve the school performance in the NAT.

3) Increase and strengthen school linkages or partnership with national/educational institutions that can contribute to school capabilities in increasing academic compliance, governance and academic achievement.

4) Include in the staff development program, seminars on enhancing teachers' capability to do research particularly on action research that will provide solutions to problems on student dropouts and achievement.

5) Include in the annual budget of the school allocation for research capability enhancement and research project implementation.

6) Conduct seminars on academic quality compliance to teachers as enhancement on their role being implementers of the program.

\section{ACKNOWLEDGMENT}

Author gratefully acknowledged City Schools Division of San Jose del Monte Bulacan, Department of Education Region III, Philippines.

\section{REFERENCE}

[1] AACCUP (2015). Official website of the Accrediting Agency of Chartered Colleges and Universities in the Philippines (AACCUP), Inc. http://www.aaccupqa.org.ph/Benefits of Accred.html

[2] Anane, C. A. (2013) Competency Based Training: Quality Delivery for Technical and Vocational Education and Training (TVET) Institutions. Educational Research International ISSN-L: 2307-3713, ISSN: 2307-3721 Vol. 2 No. 2 October 2013.

[3] Ballado-Tan, J. (2014) Attitudes towards Teaching and Work Values. International Journal of Education and Research, Vol. 2 No. 12 December 12, 2014. www.ijern.com

[4] Bernardino, J.A. (2014). Variable Related to Administrative Functions of Selected Public Secondary School Heads of Region IV-A CALABARZON for the school year 2012-2013. Dissertation, Laguna State Polytechnic University, Sta. Cruz. Laguna. 
[5] Estadilla, Eric. (2014) To Be or Not to Be: Major Choices in Budding Scientists. Print.K to 12 Program Goal: Jobs for high school graduates, Del Mundo 2013. Manila Bulletin Manila Bulletin, K-12 page 11. April, 2014

[6] Galang, U.C. (2015). "Service Quality and Client Satisfaction in Selected Universities in Metro Manila". University of the Philippines

[7] Ganal, N.N. (2014). Level of quality assurance of the teacher education program of state universities of region II: Basis for a monitoring scheme for PNU, Isabela Campus. Journal of Arts, Science \& Commerce, Vol-V, Issue-4, Oct. 2014 [49]. E-ISSN2229-4686

[8] Nuqui, A. (2015), "Student Affairs and Services among Selected Higher Education Institutions in Bulacan: A Policy Study", Bulacan State University.

[9] Uddin, S. M. A. (2010). Impact of Good Governance on Development in Bangladesh: A Study. Thesis, Roskilde University Roskilde, Denmark. Available at http://rudar.ruc.dk/bitsream/.pdf 